\title{
Resposta aos comentários
}

\author{
Ricardo Mendes \\ Centro Cultural São Paulo/Divisão de Pesquisas
}

Um cenário para agir

A proposta de discutir, por meio da seção Debates, os desdobramentos gerados pela introdução de tecnologias digitais no cotidiano das instituições de guarda de acervos fotográficos, em suas diversas facetas mas com especial interesse no gerenciamento de banco de dados e interfaces de consulta local e remota, obteve um retorno positivo.

Primeiro, pelo equilíbrio quanto à representação de diferentes campos de atuação dentro de tal panorama, com participantes de origens e experiências diversas. Segundo, pelo engajamento de pesquisadores que tiveram condições e disposição em estabelecer uma conversação.

Com certeza, o painel final não permite uma visão plena do conjunto de experiências realizadas no país. E, provavelmente, muitos projetos implantados fora dos centros de atividade mais intensa ainda não ganharam maior visibilidade, mas o crescente número de novas iniciativas deverá ter importante papel nos próximos anos, apresentando tratamentos de coleções realizados em contextos diferenciados.

A leitura dos comentários motivou a visita a novos sites ou o retorno a experiências conhecidas. Curiosa, porém, foi a reação imediata ante essas experiências. Pareceu muito instigante e prazeroso vagar por sites como o dedicado a obras raras do acervo da USP ou ao conjunto de fotografias de setor equivalente, pertencente ao acervo da Biblioteca Municipal Mário de Andrade. Mais do que a satisfação de localizar imagens em bases de dados, havia aqui uma sensação de surpresa e curiosidade estimulada, um prazer perdido.

Essa emoção de fundo despertou algumas elucubrações. Mas, agora, o importante é reconhecer o tom blasé que por vezes oculta ou rebaixa o impacto causado há alguns anos com a implantação de projetos como o Dedalus (USP) e tantos outros sistemas de bibliotecas universitárias on-line. $\bigcirc$ mesmo sentimento permitiu lembrar do prazer que obtive em meu primeiro contato com a Internet, 
em 1994, pouco antes de sua fase comercial. Na época, começavam a despontar experiências na área cultural como a página do Californian Museum of Photography (UCR) que permaneceu por muito tempo à frente de iniciativas nesse segmento.

Esse comentário final não pretende resumir as colaborações, mas sim relacionar alguns pontos que parecem de maior relevância, considerando-se o ensaio de abertura. Procura ainda destacar possibilidades e abordagens apresentadas numa leitura que não esgota o potencial dos textos individuais.

Seria oportuno começar por uma advertência. Ana Maria Camargo faz uma observação importante ao comentar o tratamento de documentos de função probatória. É necessário estabelecer essa distinção em especial porque o ensaio de abertura traça um panorama que não aponta particularidades de instituições de perfis diferenciados como arquivos, museus, etc. Documentos probatórios, textos ou imagens têm características de origem, formas, padrão de expressão e relação interdocumental típicas.

Em tal contexto especializado, em particular na esfera legal, a introdução de tecnologias digitais tem gerado não apenas uma agilização dos sistemas de gerenciamentos de dados, mas também a adoção de versões digitais de modalidades tradicionais de documentos.

No entanto, apesar de tais conjuntos documentais integrarem uma classe especial dentre a tipologia aqui abordada, fica aberta a questão de suas interfaces de recuperação, sob as mesmas condições, se for considerada uma perspectiva temporal mais ampla.

É o que ocorreu nas últimas décadas com coleções fotográficas, por exemplo, geradas por serviços de infra-estrutura urbana, cujo caráter documental foi aumentado ao serem reconhecidas posteriormente como fontes documentais por um universo de pesquisadores e interessados, muito além daqueles usuários a que se destinavam originalmente.

Curadoria e análise documentária

A leitura dos demais comentários permite apontar dois aspectos recorrentes em situações opostas. Primeiro, uma ausência de um debate focado sobre aspectos administrativos de implantação ou manutenção de sistemas de gerenciamento de dados. É curioso, considerando-se comentários sobre dificuldades de desenvolvimento de projeto. Esse "ocultamento" tem predominado nos últimos anos, em que o tópico parece ser tratado mais pelo seu caráter "administrativo", de alocação de recursos, do que pelo seu aspecto curatorial, abordagem que contemplasse não apenas a coordenação de aspectos relativos à tecnologia de hardware e software, como também procedimentos de tratamento 
de informação, recuperação de dados, interação instituição-usuário e "conteúdo", adotando expressão recorrente na esfera da produção para Internet.

$\bigcirc$ recurso ao termo curadoria não é casuístico. Embora a palavra em seu uso corrente tenha perdido algo do seu significado, ela parece a mais adequada diante da diversidade de campos de conhecimento envolvidos na matriz de decisão necessária para o desenvolvimento dessas bases de dados.

Estimulado pelos textos apresentados, acredito que além de reunir novos parceiros na produção de ferramentas atuais como designers gráficos ou web designers, seria fundamental incluir nesses projetos especialistas vindos dos serviços educativos presentes em tantas instituições ao longo da última década. Pesquisadores na área de arte-educação têm conquistado espaço em geral atendendo a um público laico. Seria estimulante que se voltassem também para os usuários especializados dessas instituições em seus diferentes níveis e campos. Tais especialistas dispõem de um conhecimento, de práticas de análise, que poderiam ser úteis na implantação, manutenção e gerenciamento de interfaces de busca para uso local ou remoto.

Rubens Ribeiro Gonçalves da Silva faz menção oportuna à posição de Walter Benjamin que apontou o potencial que

a reprodução técnica oferece em termos de preservação, em se tratando da Arte. Por outro lado, chamou a atenção para a necessidade de algum outro tipo de transmissão da memória que assegurasse sua disseminação no futuro não apenas como uma forma de representação, mas como experiência; não apenas como exibição de trabalhos artísticos, mas como uma maneira de se estabelecer uma outra relação entre tempo e memória, "como uma força germinativa suprindo metamorfoses e não apenas como imagens petrificadas de um passado morto".

segundo aspecto, que constitui uma unidade de fundo presente em quase todos os comentários, diz respeito ao tratamento de informação relativa à análise documental. $\bigcirc$ desenvolvimento de vocabulários controlados e a geração ou adoção de thesauri constituem um desafio anterior ao panorama de trabalho atual. Com certeza, o trabalho institucional sobre coleções fotográficas mais regular desenvolvido nos últimos 10 anos tem permitido visualizar a dificuldade de conciliar o uso especializado feito por determinados museus, sem no entanto ter gerado até agora o desenvolvimento de projetos coordenados.

É evidente que as coleções fotográficas constituem um campo recente de trabalho, reunindo interessados que apresentam diferentes níveis de engajamento visual. Mesmo para especialistas de áreas muito próximas, é possível esperar uma rotina de pesquisa distinta, basta tomar como exemplos um especialista em História econômica e outro em História da cultura. Mais uma vez, seria necessário pensar as interfaces de acesso como instrumentos pedagógicos, que eduquem e estimulem novas vertentes de trabalho, atividade em que a participação de especialistas em arte-educação poderia ser relevante.

Esse fundo comum entre os textos, relativo à análise documentária, cujo estudo poderia revelar nas palavras de Mauad "uma epistemologia das coleções", desenvolve-se ainda numa condição especial motivada pelo estatuto duplo da recepção da imagem na contemporaneidade tomada tanto como 
entretenimento como objeto de análise crítica. E, certamente, os portais institucionais parecem ter explorado mais aquele primeiro aspecto e muito pouco do segundo.

A análise documentária das coleções fotográficas, privilegiando a dimensão expressiva como coloca Miriam Manini, constitui um dos aspectos centrais da atual etapa de desenvolvimentos de sistemas de gerenciamento informatizado. Se no momento discutem-se descritores relativos à estrutura visual, gêneros e técnicas fotográficas (ou imagéticas), há um grande espaço para contribuições advindas do tratamento de conjuntos (ultra) especializados. Um exemplo possível é o tratamento dado às coleções de retratos do Museu Paulista que apresenta em alguns subconjuntos análises detalhadas relativas à pose e aos arranjos.

Passos importantes foram dados há mais de uma década por meio de diversas iniciativas, só para lembrar, podemos citar o Manual para catalogação de documentos fotográficos, elaborado em 1993 por um conjunto de instituições como Biblioteca Nacional, Funarte e FGV. Porém, no contexto atual, a questão ganha premência perante a expansão dos sistemas de busca de imagem. Apenas a disseminação de experiências e a consolidação dos projetos, reunindo a diversidade de recortes e profundidade e refletindo as coleções de origem, permitirão avançar.

É fundamental em tal processo o desenvolvimento paralelo dos estudos voltados para a análise crítica do perfil dessas instituições como os realizados por Mauad e Silva em momentos distintos do processo institucional. Seria importante que tais estudos institucionais constituíssem uma linha de pesquisa multidisciplinar, adotada como programa de pós-graduação ou como vertente estimulada por órgãos de fomento acadêmico.

Metáforas e interfaces

Alguns comentaristas arriscaram-se a um salto adiante: pensar as interfaces. Daniela Kutschat lembra um ponto fundamental: o da metáfora adotada para o desenho das interfaces informacionais atuais, centrada na mesa de trabalho (desktop). Qual seria a "imagem desejável" para novas interfaces de acesso a coleções fotográficas?

Em termos pessoais, ousaria apontar um aspecto não usual no contexto em discussão, o compartilhamento de experiências dos usuários. Nenhuma interface na área cultural trabalha os dados relativos aos consulentes - seu perfil e área de interesse - como elemento de feedback. Sites comerciais como os de livrarias especializadas permitem partilhar comentários (como menciona Masiero, em outro contexto), bem como relacionar a venda de livros por tema (veja Livraria Cultura, a esse respeito). Assim, partilhar resultados de busca poderia constituir uma vertente de ação. 
Ousar pensar um modelo, com todos os erros e poucos sucessos, é um empreendimento arriscado (e desejável). Em seu texto, Daniela Kutschat faz uma tentativa plausível, marcada pelo imaginário contemporâneo presente em nossos filmes, contaminados pela ambição do pan-óptico.

Outra possibilidade seria a plicar o conceito de "realidade aumentada", de forma inversa, num contexto de baixa tecnologia. Coleções fotográficas sobre cidades poderiam utilizar mapas sensíveis, associando percursos a imagens, explorando dimensões horizontais e verticais (sincronica e diacronicamente) de nossas pequenas Tróias.

Ainda no reino das metáforas aplicadas ao design de interface, retomando o mito lembrado por Kutschat da biblioteca universal, seria possível apontar um desafio oposto, o da criação da biblioteca pessoal. A proposta é ardilosa, mas a idéia seria avaliar como a biblioteca doméstica é pensada. Em especial, no presente, com tantos novos elementos como arquivos digitais, vídeos, links... (Seu bookmark é organizado? E o backup tem alguma regularidade?).

Questões práticas: rumo ao 'arquivo universal'

Os relatos de experiências pontuais como os apresentados por Breitinger e Masiero mostram a necessidade de um planejamento voltado para um horizonte mais amplo como uma estratégia clara. Nesse processo, é evidente que questões técnicas ficam ultrapassadas numa velocidade superior às das conceituais.

A necessidade de estabelecer fóruns permanentes de trabalho, reunindo todos os níveis e áreas de especialização nesse quadro diverso como trançado por Fadon, é premente. E essa aproximação possibilitará as tomadas de decisões, em especial sobre a opção por soluções próprias ou partilhadas.

Um ponto fundamental é apontado por Zaher, complementando as observações sobre a dificuldade de manutenção dos sistemas informatizados, o da preservação dos arquivos digitais. Estimulada a partir do 1 Curso LatinoAmericano de Preservação Digital realizado em 2003, na Biblioteca Nacional, a proposta de criação de uma entidade central de guarda especializada dessa nova modalidade de documentos poderia conciliar custos de implantação e manutenção com um espaço adequado para pesquisa em conservação.

Uma conclusão: apostando em novas concepções

Um elemento novo apresentado no debate, que expressa a riqueza de um horizonte de trabalho amplificado, é aquele apontado por Adams: a pesquisa artística. É uma aposta em aberto, indicativa da diversidade efetiva 
dos usuários, que pode introduzir um parceiro na organização e percepção dessas coleções.

Dentre as instituições envolvidas, os museus ocupam um local específico, pois sua matriz de usos e funções incluem, além dos objetivos educacionais e culturais, a fruição estética. Aspecto este, pouco discutido entre nós. A sugestão de criação de um programa de residência artística seria uma possibilidade de baixo custo para a avaliação dessas práticas diversas de reflexão.

O comentário de Adams traz ainda um aspecto, aparentemente secundário, quase uma lamentação, mas que merece consideração. Diz respeito ao flâneur, esse andarilho em meio à biblioteca de acesso direto. Aponta o prazer da descoberta ao acaso. E a menção permite retomar ao mesmo tempo a metáfora da biblioteca pessoal, por decorrência a possibilidade de desenhar o espaço de trabalho do pesquisador e o prazer comentado no início deste texto sobre o acesso a sites que disponibilizam edições fac-símiles.

Agora fica evidente que a satisfação de folhear aquelas obras parece refletir o aspecto multinivelado dos livros. É uma metáfora do potencial do hipertexto, que a simples consulta a um banco de dados iconográficos por meio das imagens isoladas não permite alcançar.

Talvez essa lembrança pesarosa possa levar a idear interfaces. Nessa tarefa, a cooperação dos especialistas dos serviços educativos poderá ser importante. Não apenas no desenho das interfaces de busca, mas para o estudo sobre formas de percepção da instituição por seus públicos. Um exemplo, no caso do Museu Paulista, seria a possibilidade de permitir rastrear a origem dos objetos, seus proprietários, trazer seus perfis, revelando a relação sujeito-objeto (tanto do proprietário original como do colecionador ou da instituição). Recuperar, assim, tanto as subjetividades da instituição como de seus usuários, tópicos comentados por Lima e Carvalho, o que possibilitaria eventualmente que o público (em sua diversidade) tomasse contato com as ações institucionais de forma crítica.

As interfaces de busca e os veículos em que se enquadram devem ser entendidos ao mesmo tempo como meios de comunicação e instrumentos pedagógicos. Deveriam ser vistos como expressão de uma ação curatorial conjunta atenta à diversidade dos consulentes, não sob uma óptica de relações de mercado, mas de canal de comunicação diferenciado.

Há muito por descobrir. E certamente será necessário debater e explorar. E, assim, seria o caso de aceitar o convite feito por Manini, em seu bem-humorado texto, e visitar a página na Internet criada em 2001 por Thomas Funkhouser, da Princeton University, para conhecer seu engenho de busca centrado em formas 2D e 3D.

\section{REFERÊNCIAS*}

ALMEIDA, M. C. B. de. Por uma rearquitetura dos serviços de informação em arte na cidade de São Paulo. São Paulo: ECA-USP, 1998, il. 364p. 
BARBUY, H.; CARVALHO, V. C. de; LIMA, S. F. de (Coords.). O sistema documental do Museu Paulista: a construção de um banco de dados e imagens num museu universitário em transformação. In: Imagem e produção de conbecimento. São Paulo: Museu Paulista-USP, 2002, p. 13-29.

BENJAMIN,W. A obra de arte na era de sua reprodutibilidade técnica. In: . Obras escolbidas. Magia e técnica, arte e política. São Paulo: Brasiliense, 1986, v. 1, p. 165-196.

BEARMAN, David; TRANT, Jennifer. Authenticity of digital resources: towards a statement of requirements in the research process. D-Lib Magazine, June 1998. http://www.dlib.org/dlib/ june98/06bearman.html.Acesso em 3/2/2002.

BURGI, S. Composição em branco-e-preto: os panoramas de $360^{\circ}$ de Militão Augusto de Azevedo. Cadernos de Fotografia Brasileira. $2^{\text {a }}$ ed. Rio de Janeiro: Instituto Moreira Salles, 2004.

CALLIGARIS, C.Verdades de autobiografias e diários íntimos. Estudos Históricos, Rio de Janeiro, v. 11, n. 21, 1998.

CANCLINI, N. G. Fotografia e ideologia: seus pontos comuns. In: FUNARTE/INFOTO. Feito na América Latina - II Colóquio Latino-Americano de Fotografia (México, 1981). Rio de Janeiro/México, Ministério da Cultura/Conselho Mexicano de Fotografia, 1987, p.13-18.

CARVALHO, V. C.; LIMA, S. F. Fotografias como objeto de coleção e de conhecimento. Anais do Museu Histórico Nacional, v. 32, p. 24, 2000.

CORTÉS ALONSO, Vicenta. Unidades documentales archivísticas. In: Documento y archivo de gestión: diplomática de ahora mismo. Carmona: S\&C / Universidad Internacional Menéndez Pelayo, 1994. p. 195-242.

DEPARTAMENTO DO PATRIMÔNIO HISTÓRICO. O acervo fotográfico do Departamento do Patrimônio Histórico:processamento técnico e informatização. São Paulo: SMC/DPH, 1992.

DeWITT, D. Collection Management - Going digital: Strategies for access, preservation, and conversion of collections to a digital format, v. 22, n. 3/4, 223 p., 1998.

DURANTI, Luciana.The concept of appraisal and archival theory. The American Archivist, Chicago (II.), v. 57, n. 2, 1994, p. 328-344.

FERREZ, G. A fotografia no Brasil e um dos seus mais dedicados servidores: Marc Ferrez. Revista do Patrimônio Histórico e Artístico Nacional, Rio de Janeiro, v. 10, 1946.

FONTCUBERTA, J. (Ed.). Fotografía: crisis de historia. Barcelona: Actar, 2003.

GONZÁLEZ GARCÍA, P. Los documentos en nuevos soportes. Boletim do Arquivo, São Paulo, v. 1, n. 1, p. 19-37, 1992.

HIRSZMAN, M. Fotografia brasileira ganha seu maior arquivo. Jornal da Tarde, São Paulo, p. 8c, 24/4/1997. (sobre Instituto Cultural Itaú). 
INSTITUTO ITAÚ CULTURA. Banco de dados informatizado: módulo fotografia. Setor Memória fotográfica da cidade de São Paulo. Instruções ao consulente. São Paulo: Centro de Informática e Cultura - Itaú, 1992.12p.

KETELAAR, Eric. Can we trust information? In: The archival image: collected essays.Amsterdam: Hilversum, 1997. p. 119-124.

KOSSOY, B. Fotografia e história. 2 ed. São Paulo: Ateliê Editorial, 2001.

.Os tempos da fotografia. In: II ENCUENTRO NACIONAL DE FOTOTECAS, 2001b, México. Alquimia, n. 13, setembro/dezembro 2001, Sistema Nacional de Fototecas.

LE GOFF, J. Documento/Monumento. In: Encilopédia Einaudi, Memória-História, v. 1, Lisboa: Impr. Nacional-Casa da Moeda, 1995.

LÉVY, P. As tecnologias da inteligência - o futuro do pensamento na era da informática. São Paulo: Ed. 34, 1993, 208 p.

MANINI, M. P. Análise documentária de fotografias: um referencial de leitura de imagens fotográficas para fins documentários. 2002. Tese (Doutorado em Ciências e Comunicação) Escola de Comunicações e Artes, Universidade de São Paulo, 2002.

.Análise documentária de fotografias:leitura de imagens incluindo sua dimensão expressiva. Cenário Arquivístico, Brasília, v. 3, n. 1, jan.-jun. 2004.

MENESES, U. T. B. de. Memória e cultura material: documentos pessoais no espaço público. Estudos Históricos, Rio de Janeiro, v. 11, n. 21, 1998.

MENNE-HARITZ,Angelika.Appraisal or selection: can a content oriented appraisal be harmonized with the principle of provenance? In:The principle of provenance:report from the First Stockholm Conference on Archival Theory and the Principle of Provenance: 2-3 September 1993. Stockholm: Riksarkivet, 1994.p. 103-131.

MIRANDA, A. L. C. Globalización y sistemas de información: nuevos paradigmas e nuevos desafíos. Ciência da Informação, Brasília, v. 25, n. 3, p. 308-313, 1996.

PAYNE, A. Research and the Artist. Considering the Role of the Art School. Oxford: Ruskin School of Drawing and Fine Art, 2000.

RIEUSSET-LEMARIÉ, I. Web Museums and Memory in the Age of Digital Multimedia Networks (Extensions of Walter Benjamin's Insights). Archives E Museum Informatics. Disponível em: http://www.archimuse.com/mw2000/papers/rieusset/rieusset.html. Acesso em: 29/11/2003.

SANTOS, B. S. Um discurso sobre as ciências. 8 ed. Porto: Afrontamento, 1987.

SHATFORD, S. Describing a picture: a thowsand words are seldom cost effective. Cataloging and Classification Quarterly, New York, v. 4, n. 4, p. 13-29, 1984. 
Analyzing the subject of a picture: a theoretical approach. Cataloging and Classification Quarterly, New York, v. 6, n. 3, p. 39-62, 1986.

SHATFORD LAYNE, S. Some issues in the indexing of images. Journal of the American Society for Information Science, v. 45, n. 8, p. 583-588, 1994.

SILVA, R. R. G. da. Digitalização de acervos fotográficos públicos e seus reflexos institucionais e sociais: tecnologia e consciência no universo digital. 2002. 269 f.Tese (Doutorado em Ciência da Informação) - Escola de Comunicação, Universidade Federal do Rio de Janeiro, Instituto Brasileiro de Informação em Ciência e Tecnologia, Rio de Janeiro, 2002.

Por um novo modo de olhar: fotografia, informação e consciência. In: V ENANCIB ENCONTRO NACIONAL DE PESQUISA EM CIÊNCIA DA INFORMAÇÃO: INFORMAÇÃO, CONHECIMENTO E TRANSDISCIPLINARIDADE, 2003, Belo Horizonte. Anais... Belo Horizonte, 2003.

SMIT,J.W. Análise documentária: a análise da síntese. 2 ed. Brasília: IBICT, 1989.

. Novas tecnologias e bancos de imagens. In: XII ENCONTRO REGIONAL DE HISTÓRIA Anpuh, Campinas, 5 a 7/9/1994.

.A representação da imagem. Informare, Rio de Janeiro, v. 2, n. 2, p. 28-36, jul.-dez. 1996.

Propostas para a indexação de informação iconográfica, 1997. (mimeo).

SONTAG, S. Ensaios sobre a fotografia. Rio de Janeiro: Arbor, 1981.

WARNIER J.-P. Culture matérielle et subjectivation.In:PARLEBAS, P.(Coord.). Le corps et le langage: parcours accidentés. In: JOURNÉE DE L'ÉCOLE DOCTORALE "ÉDUCATION, LANGAGE, SOCIETÉ", nov. 1999, Paris. Actes... Paris: Université Paris V - René Descartes, L’Harmattan, 1999a.

Construire la culture matérielle. L’homme qui pensait avec ses doigts. Paris: Presses Universitaires de France, 1999b.

Sites

Architectural ans Arts Thesaurus (gethy Foundation) - http://www.getty.edu/art/collection

Biblioteca Nacional (RJ) - http://www.bn.br

Building Digital Collections: Technical Information about American Memory Collections. http://lcweb2.loc.gov/ammem/techdocs/digcols.html, acesso em dezembro de 2004.

Californian Museum of Photography (CMP) - http://www.cmp.ucr.edu

Centro de Documentação de Bens Patrimoniais (programa SUR) - http://www.surdoc.cl

FUNKHOUSER,T. - http://shape.cs.princeton.edu/search.html 
Iconclass (Warburg Institute) - http://www.iconclass.nl

Image Permanence Institute - http://www.rit.edu

Laboratório de História Oral e Imagem - http://www.historia.uff.br/labhoi/ofic.htm

Obras raras (USP) - http://www.obrasraras.usp.br

Obras raras (SMC/BMMA) - http://www.prefeitura.sp.gov.br

Patrimônio Fotográfico (Chile) - http://www.patrimoniofotografico.udp.cl

Princeton Shape Retrieval \& Analysis Group - http://shape.cs.princeton.edu/search.html

Sistema Nacional de Fototecas do México - http://www.sinafo.inah.gob.mx

Sygma/Corbis - http://www.observatorio.ultimosegundo.ig.com.br/artigos/asp2702200297.htm 